\title{
Erratum to: Is Routine Preoperative Esophagogastroduodenoscopy Screening Necessary Prior to Laparoscopic Sleeve Gastrectomy? Review of 1555 Cases and Comparison with Current Literature
}

\author{
Asaad Salama $^{1}$ Tamer Saafan $^{2}$ - Walid El Ansari ${ }^{3,4,5}$ - Mohsen Karam ${ }^{1}$. \\ Moataz Bashah ${ }^{1}$
}

Published online: 26 July 2017

(C) Springer Science+Business Media, LLC 2017

\section{Erratum to: OBES SURG \\ DOI 10.1007/s11695-017-2813-4}

There was an error in the title of the original article. Esophagogastroduodenoscopy was misspelled. It is correct here. Also, some author affiliations were omitted in the original article. They are presented correctly here.

The online version of the original article can be found at http://dx.doi.org/ 10.1007/s11695-017-2813-4

Asaad Salama

asaadfayrouz@live.com

1 Department of Bariatric Surgery, Hamad General Hospital, Hamad Medical Corporation, Doha, Qatar

2 Department of General Surgery, Hamad General Hospital, Hamad Medical Corporation, Doha, Qatar

3 Department of Surgery, Hamad General Hospital, Hamad Medical Corporation, Doha, Qatar

4 College of Medicine, Doha, State of Qatar

5 School of Health and Education, University of Skövde, Skövde, Sweden 